\title{
Evaluation of larvicidal activity and brine shrimp toxicity of rhizome extracts of Zingiber zerumbet (L.) Smith
}

\author{
Augusto Bücker ${ }^{[1]}$, Nádia Cristina Falcão-Bücker ${ }^{[2]}$, Cecília Veronica Nunez ${ }^{[2]}$, \\ Carlos Cleomir de Souza Pinheiro ${ }^{[2]}$ and Wanderli Pedro Tadei ${ }^{[3]}$
}

[1]. Departamento de Biotecnologia, Universidade do Estado do Amazonas, Manaus, AM. [2]. Laboratório de Bioprospecção e Biotecnologia, Instituto Nacional de Pesquisas da Amazônia, Manaus, AM. [3]. Laboratório de Malária e Dengue, Instituto Nacional de Pesquisas da Amazônia, Manaus, AM.

\begin{abstract}
Introduction: In this study, we used dichloromethane (DCM) and methanol (MeOH) extracts of the Zingiber zerumbet rhizome to evaluate brine shrimp lethality and larvicidal activity on Aedes aegypti and Anopheles nuneztovari mosquitoes. Methods: Bioassays were performed by exposing third-instar larvae of each mosquito species to the DCM or MeOH extracts. Results: Probit analysis with DCM and $\mathrm{MeOH}$ extracts demonstrated efficient larvicidal activity against $A$. aegypti and A. nuneztovari larvae. Conclusions: The DCM and $\mathrm{MeOH}$ extracts showed higher activity against $A$. nuneztovari larvae than against $A$. aegypti larvae, suggesting that the extracts have species-specific activity.
\end{abstract}

Keywords: Larvicide. Rhizomes. Zingiber zerumbet.

Zingiber zerumbet (L.) Smith, popularly known as gengibre amargo (bitter ginger), is an Asiatic plant introduced into the Amazon region that has long been used in Asian popular medicine for treating a number of illnesses. The literature shows that some compounds isolated from the essential oil of $Z$. zerumbet, such as zerumbone, humulene, zederone, and camprene, possess anti-inflammatory, antiviral, antitumor, antioxidant, antiallergic, and antimicrobial activities ${ }^{1,2}$. Zederone, a sesquiterpene compound, has been suggested to contribute to the larvicidal activity of the ethanol extract ${ }^{3}$.

Tropical diseases like dengue and malaria still represent a major public health concern, mainly in developing countries ${ }^{4}$. Recently, to treat these diseases, botanical and microbial insecticides have been increasingly used for mosquito control because of their efficacy and documented non-toxic effects on non-target organisms ${ }^{5}$. Mosquito larval control may prove to be an effective tool that can be incorporated into integrated vector management strategies for reducing malaria transmission ${ }^{6}$.

The promising larvicidal potential of $Z$. zerumbet essential oils has been recently reported in literature ${ }^{2}$. The aim of the present investigation was to evaluate the brine shrimp lethality and larvicidal potential of $Z$. zerumbet rhizome extracts. The larvicidal assay was performed against larvae of 2 mosquito species (Aedes aegypti and Anopheles nuneztovari). This plant was selected because it has been used for cancer treatment and

Address to: Dr. Augusto Bücker. Laboratório de Malária e Dengue - LMD/ INPA. Caixa Postal 478. Av. André Araújo 2936, Bairro Aleixo, 69083-000 Manaus, AM, Brasil.

Phone: 5592 3643-3364; Fax: 5592 3642-3435

e-mail: abucker@gmail.com

Received 17 August 2011

Accepted 07 December 2011 it also exhibits antimicrobial activity ${ }^{1}$, while only a few studies on its larvicidal activity have been reported ${ }^{7,8}$.

Rhizomes of Z. zerumbet were collected from the Tarumã River region, Manaus, AM, Brazil $\left(03^{\circ} 00^{\prime} 05^{\prime \prime} \mathrm{S}\right.$ and $\left.60^{\circ} 05^{\prime} 01^{\prime \prime} \mathrm{W}\right)$. The rhizomes were crushed, dried, macerated with dichloromethane (DCM) for $72 \mathrm{~h}$, and then filtered. The plant material was dried, extracted with methanol $(\mathrm{MeOH})$, for $72 \mathrm{~h}$, and filtered. The extracts obtained were concentrated in a low-pressure rotary evaporator to remove excess solvent. The extracts were redissolved in dimethylsulfoxide (DMSO) for further tests. A voucher specimen was deposited in the herbarium of Instituto Nacional de Pesquisas da Amazônia (INPA) (Number 186913).

Both mosquito species were maintained for oviposition in the insectary at $26 \pm 2^{\circ} \mathrm{C}$, with a photoperiod of $12: 12$ (L/D) and a relative humidity of $80-90 \%$, according to the criteria of Scarpassa and Tadei ${ }^{9}$.

Aedes aegypti Linnaeus, 1762: Eggs were obtained from the colonies of the Malaria and Dengue Laboratory (INPA) and they were kept in insectaria cages.

Anopheles nuneztovari Gabaldón, 1940: Species collections of the genus Anopheles were carried out at Natan Farm in the east region of Manaus City, State of Amazonas, Brazil $\left(03^{\circ} 04^{\prime} 10^{\prime \prime} \mathrm{S}\right.$ and $\left.59^{\circ} 51^{\prime} 40^{\prime \prime} \mathrm{W}\right)$. Catches were carried out in cattle pens, and only fed females were selected. Samples were collected using an entomological manual captor between 18 and $21 \mathrm{~h}$.

The larvicidal bioassay was carried out using 5 different doses of the DCM and $\mathrm{MeOH}$ extracts of $Z$. zerumbet rhizomes. Ten third-instar larvae of each mosquito species were used and $50 \mu \mathrm{L}$ of liquid food added containing DCM or $\mathrm{MeOH}$ extracts at concentrations of $100,200,300,400$, or $500 \mu \mathrm{g} / \mathrm{mL}$. In each case, 4 replicates of each concentration were assayed. The negative control received only DMSO at the same concentration and a $10 \%$ mortality rate and a $95 \%$ confidence interval were set as 
the limits. Readings were collected at 24,48 , and $72 \mathrm{~h}$, recording the number of live and dead larvae at each concentration. The larvae were considered dead if they were immobile and unable to reach the water surface.

The extracts were evaluated for lethality to brine shrimp larvae (Artemia salina Leach) according to the procedure described by Meyer et al. ${ }^{10}$ with some modifications. Briefly, dried brine shrimp eggs were bred in saline medium (Instant Ocean $\left.{ }^{\circledR}\right)$. After $48 \mathrm{~h}$, a few shrimps hatched and were ready for testing. One-day-old larvae (10 per vial) were transferred into 5 -mL vials containing saline solution along with 25,50 , $100,250,500$, or $1,000 \mu \mathrm{g} / \mathrm{mL}$ of each DCM and $\mathrm{MeOH}$ extract dissolved in DMSO and diluted serially in saline water. In each case, 4 replicates of each concentration were assayed. After 24h, the survivors were counted and the percentage mortality at each dose was recorded. A saline solution containing DMSO (1\%) was used as the negative control $\left(\mathrm{LC}_{50}>1,000 \mu \mathrm{g} / \mathrm{mL}\right)$, while colchicine $\left(\mathrm{LC}_{50}=25 \mu \mathrm{g} / \mathrm{mL}\right)$ was used as the positive control ${ }^{11}$.

For statistical analysis, the lethal concentration $\left(\mathrm{LC}_{50}\right.$ and $\mathrm{LC}_{90}$ ) was calculated using Probit analysis. The percentage mortality was calculated and mortality corrections when necessary were carried out using Abbot's formula.

The brine shrimp lethality assay is considered a useful tool for preliminary toxicity assessment, to screen medicinal plants popularly used for several purposes, and for monitoring the isolation of a great variety of biologically active compounds ${ }^{12}$. The method is rapid, simple, reproducible, and economical. This in vivo test has been successfully employed for bioassayguide fractionation of active cytotoxic and antitumor agents ${ }^{1}$.
Furthermore, positive correlations have been demonstrated between the antimicrobial ${ }^{12}$ and larvicida ${ }^{13}$ activities, and lethality to brine shrimp and the corresponding lethal dose of medicinal plants.

The results of Artemia salina testing are summarized in Table 1 (mortality $\%$ and $\mathrm{LC}_{50}-\mathrm{LC}_{90}$ ). The results revealed that $Z$. zerumbet extracts showed significant toxicity against Artemia salina for up to $48 \mathrm{~h}$, with an $\mathrm{LC}_{50}$ of $30.9 \mu \mathrm{g} / \mathrm{mL}$ for the DCM extract, and an $\mathrm{LC}_{50}$ of $64.0 \mu \mathrm{g} / \mathrm{mL}$ for the $\mathrm{MeOH}$ extract. These results are consistent with the results of Déciga-Campos et $\mathrm{al}^{11}$, who reported $\mathrm{LC}_{50}$ values ranging from 37 to $227 \mu \mathrm{g} / \mathrm{mL}$, and of Bastos et al ${ }^{12}$, who reported an $\mathrm{LC}_{50}$ of $29.55 \mu \mathrm{g} / \mathrm{mL}$ for hexane acid and an $\mathrm{LC}_{50}$ of $398.05 \mu \mathrm{g} / \mathrm{mL}$ for a $1: 1$ mixture of hexane- $\mathrm{CHCl}_{3}$ (Table 1).

Larvicide activity involves applying chemicals to habitats to kill pre-adult mosquitoes. This experiment validates and reveals the efficacy of the DCM and $\mathrm{MeOH}$ extracts of $Z$. zerumbet against $A$. aegypti and A. nuneztovari larvae. Furthermore, a positive correlation was observed between the concentration of the extract and the mortality percentage (Tables $\mathbf{1}$ and 2), with the mortality rate being directly proportional to concentration. Bioassays showed that the DCM extract was more toxic than the $\mathrm{MeOH}$ extract to the larvae of both mosquito species, and that $A$. nuneztovari $\left(\mathrm{CL}_{50}<70 \mu \mathrm{g} / \mathrm{mL}\right)$ was more susceptible to the DCM extract than A. aegypti $\left(\mathrm{CL}_{50}<300 \mu \mathrm{g} / \mathrm{mL}\right)$ in both treatments (Table 2). Zerumbone is the main common component (31.7\%) in the rhizome oil of the Asian species of Z. zerumbet ${ }^{8}$, and $97 \%$ pure zerumbone was obtained from the essential oil of the rhizomes of the Brazilian species ${ }^{14}$. Based on

TABLE 1 - Percentage mortality of brine shrimp (Artemia salina), and Aedes aegypti and Anopheles nuneztovari larvae, at different time intervals and with different Zingiber zerumbet dichloromethane and methanol extract concentrations.

\begin{tabular}{|c|c|c|c|c|c|c|c|c|}
\hline Specimen & \multicolumn{8}{|c|}{ Brine Shrimp (\%) } \\
\hline \multirow[t]{5}{*}{ Artemia salina } & methanol & 24 & 98.0 & 94.4 & 80.0 & 53.3 & 11.2 & 2.2 \\
\hline & & 48 & 100.0 & 100.0 & 98.8 & 70.0 & 43.3 & 20.2 \\
\hline & dichloromethane & 24 & 100.0 & 96.6 & 94.4 & 86.7 & 46.7 & 38.9 \\
\hline & \multicolumn{8}{|c|}{ Larvicidal activity (\%) } \\
\hline & & Time (h) & $1,000 \mu \mathrm{g} / \mathrm{mL}$ & $500 \mu \mathrm{g} / \mathrm{mL}$ & $400 \mu \mathrm{g} / \mathrm{mL}$ & $300 \mu \mathrm{g} / \mathrm{mL}$ & $200 \mu \mathrm{g} / \mathrm{mL}$ & $100 \mu \mathrm{g} / \mathrm{mL}$ \\
\hline \multirow[t]{2}{*}{ Aedes aegypti } & methanol & 48 & not calculated & 95.0 & 78.3 & 50.0 & 18.3 & 2.5 \\
\hline & & 72 & not calculated & 99.1 & 94.2 & 67.5 & 37.5 & 5.0 \\
\hline & & 72 & not calculated & 100.0 & 97.5 & 93.3 & 90.8 & 68.3 \\
\hline & dichloromethane & 48 & not calculated & 100.0 & 95.8 & 94.2 & 92.5 & 68.3 \\
\hline & & 72 & not calculated & 100.0 & 99.1 & 98.3 & 97.5 & 78.3 \\
\hline
\end{tabular}


TABLE 2 - Lethal concentration of Zingiber zerumbet dichloromethane and methanol extract against brine shrimp (Artemia salina) and Aedes aegypti and Anopheles nuneztovari larvae at different time intervals.

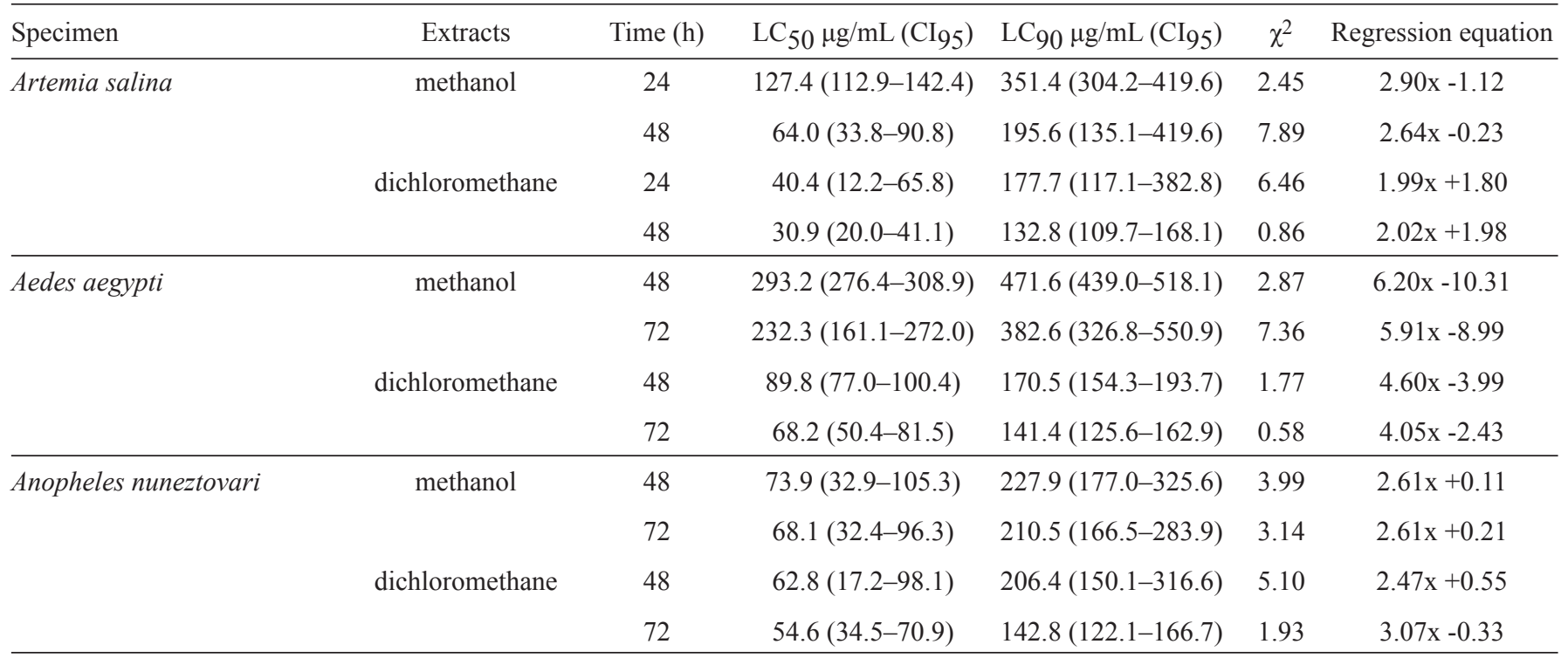

$\mathrm{LC}_{50}$ : median lethal concentration; CI: confidence interval; $\mathrm{LC}_{90}: 90 \%$ lethal concentration; $\chi^{2}$ : chi-square.

these results, the authors suggest that the high activity present in the DCM extract might be associated with a considerable amount of the active principal of $Z$. zerumbet, which would cause the greater susceptibility of the tested organisms (brine shrimp and mosquito larvae) (Table 2). Rahuman et al..$^{15}$ evaluated the larvicidal activity of the petroleum ether extract of $Z$. officinalis, and their results show that the most effective compound against A. aegypti (4.25ppm) and Culex quinquefasciatus (5.52ppm) was 4-gingerol. Sutthanont et al. ${ }^{8}$ have reported that the essential oils of Z. zerumbet and Kaempferia galanga, two Zingiberaceae, were found to be larvicidal against pyrethroid-susceptible A. aegypti, with $\mathrm{LC}_{50}$ values of 48.88 and $53.64 \mathrm{ppm}$, respectively. Tewtrakul et al. ${ }^{7}$ reported the effective toxicity of the ethanol extract of $Z$. zerumbet against Anopheline larvae, with an $\mathrm{LD}_{50}$ of $18.9 \mu \mathrm{g} / \mathrm{mL}$. However, the biological activity of $Z$. zerumbet as a larvicide has not been studied so far.

In conclusion, the present findings support the use of $Z$. zerumbet as an alternative to combat mosquito vectors of diseases. The results reported here pave the way for further investigations into the larvicidal properties of natural product extracts. We are currently testing the zerumbone component from the rhizomes of $Z$. zerumbet ${ }^{14}$.

\section{CONFLICT OF INTEREST}

The authors declare that there is no conflict of interest.

\section{FINANCIAL SUPPORT}

Financial support was provided by Instituto Nacional de Pesquisas da Amazonia (INPA), of the Conselho Nacional de Pesquisa Científica (CNPq) and the Fundação de Amparo à Pesquisa do Estado do Amazonas (FAPEAM).

\section{REFERENCES}

1. Abdul AB, Abdelwahab SI, Al-Zubairi AS, Elhassan MM, Murali SM. Anticancer and antimicrobial activities of zerumbone from the rhizomes of Zingiber zerumbet. Int J Pharmacol 2008; 4:301-304.

2. Yob NJ, Jofrry SM, Affandi MMRMM, Teh LK, Salleh MZ, Zakaria ZA. Zingiber zerumbet (L.) Smith: A Review of Its Ethnomedicinal, Chemical, and Pharmacological Uses. Evid Based Complement Alternat Med 2011; 2011:1-12.

3. Kader MG, Habib MR, Nikkon F, Yeasmin T, Rashid MA, Rahman MM, et al. Zederone from the rhizomes of Zingiber zerumbet and its anti-staphylococcal activity. Bol Latinoam Caribe Plant Med Aromat 2010; 9:63-68.

4. Tadei WP, Dutary-Thatcher B, Santos JMM, Scarpassa VM, Rodrigues IB, Rafael MS. Ecologic observations on anopheline vectors of malaria in the Brazilian Amazon. Am J Trop Med Hyg 1998; 59:325-335.

5. Vyas N, Dua K, Prakash S. Efficacy of Lagenidium giganteum metabolites on mosquito larvae with reference to nontarget organisms. Parasitol Res 2007; 100:385-390.

6. Becker N. Bacterial control of vector-mosquitoes and black flies. In: Charles JF, Delécluse A, LeRoux CN, editors. Entomopathogenic bacteria: from laboratory to field application. Dordrecht: Kluwer Academic Publishers; 2000. p. 383-398.

7. Tewtrakul S, Itchayapruk J, Chaitongruk P. Mosquito larvicidal activity of Zingiber zerumbet Smith rhizomes. Songklanakarin J Sci Technol 1998; 20: 183-187.

8. Sutthanont N, Choochote W, Tuetun B, Junkum A, Jitpakdi A, Chaithong U, et al. Chemical composition and larvicidal activity of edible plant-derived essential oils against the pyrethroid-susceptible and -resistant strains of Aedes aegypti (Diptera: Culicidae). J Vector Ecol 2010; 35:106-115.

9. Scarpassa VM, Tadei WP. Biologia de anofelinos amazônicos. XIII. Estudo do ciclo biológico de A. nuneztovari. Acta Amaz 1990; 20:95-118.

10. Meyer BN, Ferrigni NR, Putnam JE. Brine shrimp: A convenient general bioassay for active plant constituents. Planta Med 1982; 45:31-34.

11. Déciga-Campos M, Rivero-Cruz I, Arriaga-Alba M, Castañeda-Corral G, Angeles-López GE, Navarrete A, et al. Acute toxicity and mutagenic activity of Mexican plants used in traditional medicine. J Ethnopharmacol 2007; 110:334-342. 
12. Bastos MLA, Lima MRF, Conserva LM, Andrade VS, Rocha EMM, Lemos RPL. Studies on the antimicrobial activity and brine shrimp toxicity of Zeyheria tuberculosa (Vell.) Bur. (Bignoniaceae) extracts and their main constituents. Ann Clin Microbiol Antimicrob 2009; 8:16.

13. Leite JJG, Brito ÉHS, Cordeiro RA, Brilhante RSN, Sidrim JJC, Bertini LM, et al. Chemical composition, toxicity and larvicidal and antifungal activities of Persea americana (avocado) seed extracts. Rev Soc Bras Med Trop 2009; 42:110-113.
14. Pinheiro CCS (inventor), Instituto Nacional de Pesquisas da Amazônia (assignee). Processo de obtenção de zerumbona isolada dos óleos essenciais das raízes de Zingiber zerumbet L. Smith (Zingiberaceae). Brazilian patent BR PI0505343-9 A2; 2005.

15. Rahuman AA, Gopalakrishnan G, Venkatesan P, Geetha K. Isolation and identification of mosquito larvicidal compound from Abutilon indicum (Linn) Sweet. Parasitol Res 2008; 102:981-988. 